\title{
Level of Household Satisfaction in Community Baesd Health Insurance Beneficiaries on Medical Laboratory Services and Its Associated Factors in Selected Health Centers
}

\author{
Dawit Gashaw \\ PO Box 359, Addis Ababa, Ethiopia
}

\begin{abstract}
Background: Community-based health insurance (CBHI) scheme are emerging and growing tool for providing financial protection to deprived individuals against health-related events. And community based health insurance an emerging alternatives to increase primary health care accesses. There is an increasing interest in the role of $\mathrm{CBHI}$ scheme in improving equity and access to essential health care of the poor society's particularly informal sector worker. On CBHI benefit package including both outpatient and in-patient services utilization at public facilities, enrolled household may not seek care in private health facilities unless a particular services or drug is unavailable at public health facilities. The scheme exclude treatment abroad and treatment with large cosmetics value such as artificial teeth and plastic surgery.

Objective: To assess the level of household satisfaction in community based health insurance beneficiaries on medical laboratory services and associated factors in selected health center, Addis Ababa Ethiopia.

Methods: Cross sectional study was conducted by using both quantitative collection methods data was collected by structured questionnaire. Quantitative data was entered analyzed using SPSS version Descriptive statistics, bivariate and a multivariable logistic regression analysis was performed. A 5-point Likert scale with 1 and 5 indicating the lowest and highest levels of satisfaction, respectively, was used and their weighted average was used to categorize the satisfaction level of the patients.

Result: Among the 366 CHBI beneficiaries, 194(53\%\%) were satisfied, 111(30.3\%\%) were Neutral and $61(16.7 \% \%)$ were dissatisfied with general Laboratory service provided, There was no significant association between socio-demographic characteristics and level of satisfaction of patients (P-value > 0.05) In Likert Scale, the overall mean rate of satisfaction of patients with laboratory services selected health center was 3.5 out of the 5 points. The lowest mean rating of satisfaction were given availability of service provider explained about diagnostic test during sample collection and Cleanliness and comfort of the latrine of 2.79 and 2.96 respectively.

Conclusion: The overall Household's satisfaction in CBHI beneficiaries on medical laboratory service done in selected health centers in Addis Ababa was 53\%.

The level of satisfaction of the patients was no statistically significant association by age, sex, educational level, marital status and religion. The availability of service provider explained about diagnostic tests during sample collection ,cleanness and comfort of the latrine and insufficient waiting area also unavailability of educating and entertaining materials was the main cause of low rating in the overall level of satisfaction in CBHL beneficiaries. Keywords: - community based health insurance, household satisfaction, laboratory service
\end{abstract}

DOI: $10.7176 / \mathrm{FSQM} / 98-04$

Publication date:June $30^{\text {th }} 2020$

\section{Background}

In the developing countries people faced a considerable challenge in financial health care. Public services are unavailable and unaffordable to the majority of poor people in the difficulty to get those services in those countries. Millions of people in the developing country still suffer and die from health related conditions for which effective but under-utilized interventions exist (1).

Those developing Countries should reduce direct payments of health care by introducing health insurance scheme and health insurance can be complementary or alternative source of health care finance that has been implemented in those poor countries(2).

In June 2011, as part of its health sectors financing reform (HSFR) initiatives, the Ethiopian government launched a pilot CBHI scheme in 13 district in four main regions(Tigray, Amhara, Oromia and SNNPS) of the country(3)

Patient satisfaction is an important indicator of health care quality and often associated with greater adherence to medical technology, health services utilization and health outcomes in the community based health insurance program. One of the measurements to identify the quality delivery of medical laboratory services for clients is by assessing the customer satisfaction has a great roll. Furthermore client experience and opinion are very crucial for improving health care services, shaping health polices and providing feedback on the quality, availability and responsiveness of medical laboratory services (4).

Already there has been insufficient knowledge and awareness of the health insurance activities by those 
enrolled in the scheme. Complaints have arisen where providers denied enrollees their full entitlements and some providers have charged additional fees on the pretext of non-inclusion of the service in the benefit package. Again, Insured-persons have complained of poor attitude and behavior of service providers operating in the health insurance scheme. Assessing the appropriateness of care and clients satisfaction is crucial to have assured the continuous attractiveness of the care contracted (5).

The laboratory patient satisfaction studies in Community based health insurance have been carried out in Ethiopia has not much, researchers based their study on to the regional state hospitals or rural areas with an exception of very few studies. Even those studies which is not include CBHI have been made in Addis Ababa were restricted to only antiretroviral therapy monitoring laboratory services. Given the lack of adequate study on the matter and the new lunched program (CBHI) in Addis Ababa more studies need to be conducted periodically on the general laboratory services. Hence, my study attempts to assess the patient satisfaction of community Based Health insurance beneficiaries on laboratory services received at selected health centers, Addis Ababa, Ethiopia.

\section{Objective of the study \\ General objective \\ $>$ To assess the level of household satisfaction in community based health insurance beneficiaries on medical laboratory services and associated factors in selected health center, Addis Ababa Ethiopia December 2019 to March 2020 G.C. \\ Specific objective \\ $>$ To assess the level of house hold satisfaction in community based health insurance beneficiaries on medical laboratory services in selected health centers, Addis Ababa Ethiopia. \\ $>$ To describe factors associated with household satisfaction in community based health insurance beneficiaries on medical laboratory services.}

\section{Materials and method Study area and period}

The study was conducted in two selected health centers in Addis Ababa was conduct from December 2019 to March 2020 G.C, those are Felege melese health center and Ras emeru health center. Those health centers are selected randomly from model health centers in the city and also in the sub city based on the performance on community based health insurance program, number of clients members in this program and availability of sustainable laboratory services, those health centers selected from deferent sub city which makes the data was representative.

\section{Sample size determination and sampling}

The sample size was determined by using single proportion and assuming the proportion is $50 \%$ most of the research done overall satisfaction of the households in CBHI not specifically the satisfaction of the household on community based health insurance in medical laboratory service and with $5 \%$ marginal error and $95 \%$ confidence interval of certainty (alpha $=0.05$ ). Based on this assumption, the actual sample size for the study is computed using one-sample population proportion formula as indicated below. Where: $\mathrm{n}=$ Sample size $\mathrm{z}=$ critical value $1.96 \mathrm{p}=$ assume stabilized adherence prevalence rate $50 \% \mathrm{~d}=$ precision (marginal error) $=0.05$ Thus the sample size is $\mathrm{n}=(1.96) 2 \times 0.5(1-0.5) 0.052=384$

Since $\mathrm{N}$ : 6433 which is $<10,000$ we use $\mathrm{nf}=\mathrm{n} / 1+1 / \mathrm{N} ; 384+384 / 1+1 / 6433=366$ so my sample size is $\mathbf{3 6 6}$. The study participants selected from source population using simple random sampling

\section{Data collection methods}

Data was collected by face to face interview through using structured pre-tested interviewer-administered questionnaire. One day prior to the beginning of actual data collection. the data collectors ( 2 medical laboratory technicians ) who work in selected health centers will be trained in order to have a common understanding on each question. During the training, the importance of obtaining the respondents verbal consent and respecting their rights to respond and not to respond to any part of a question will be emphasized in addition to ensuring the respondents privacy and confidentiality. And also the data collection was supervised by the principal investigator; the questioners was prepared in English and translated to local language Amharic and the back to English to verify the translation. Beside their socio-demographic characteristics study participants asked to rate each aspects of their laboratory services on a five-point scales (very dissatisfied, dissatisfied, Neutral, Satisfied, and very satisfied).

The overall rate of satisfaction by Likert scale was calculated as (No. of very satisfied rating x5) + (No. of satisfied rating $\times 4)+($ No. of Neutral rating $\times 3)+($ No. of Dissatisfied rating $x 2)+($ No. of very dissatisfied rating $\mathrm{x} 1)$ divided by the total number of ratings (1-5) for the specific laboratory service. Association between sociodemographic characteristics of patients and level of satisfaction on laboratory services was determined by using Chi-square test. P-value $<0.05$ was considered as statistically significant. 


\section{Ethical consideration}

Ethical approval was obtained from Addis Ababa university department of medical laboratory science and permission was obtained from each selected health centers. Informed consent was obtained from each of the study participant after explanations of the importance of the study. They were having all the right not to be included in the study or not to answer any questions or withdraw anytime they want. They were also being informed that the data they provided was strictly confidential and privacy of the study participants was highly maintained.

\section{Results}

Socio-demographic characteristics of the participants

A total of 366 community based health insurance beneficiaries were enrolled in the study and the response rate was $100 \%$. 226(61.7\%) of respondents were female, , The majority $130(35.5 \%)$ of the participants lie within the age group of 35-45 years, The smaller group 11(3\%) consists of those aged $>55$ years, Also this table showed that most of the respondents had attended at least secondary school education 112(30.6\%) and About $199(54.4 \%)$ of them were Orthodox Christians and 205(56\%) were married. (Table1).

Table 1 socio-demographic characteristics of respondents on patient satisfaction with clinical laboratory services received at, selected health center Addis Ababa, $2020(n=366)$

\begin{tabular}{|c|c|c|c|}
\hline No & Variable & frequency & Percentage \\
\hline \multirow[t]{6}{*}{1} & Age & & \\
\hline & $18-24$ & 56 & $15.3 \%$ \\
\hline & $25-34$ & 120 & $32.8 \%$ \\
\hline & $35-44$ & 130 & $35,5 \%$ \\
\hline & $45-54$ & 49 & $13.4 \%$ \\
\hline & $>55$ & 11 & $3.0 \%$ \\
\hline \multirow[t]{3}{*}{2} & Sex & & \\
\hline & Male & 140 & $38.3 \%$ \\
\hline & Female & 226 & $61.7 \%$ \\
\hline \multirow[t]{4}{*}{3} & Marital status & & \\
\hline & Married & 205 & $56.0 \%$ \\
\hline & Single & 147 & $40.2 \%$ \\
\hline & Divorced & 14 & $3.8 \%$ \\
\hline \multirow[t]{6}{*}{4} & Educational Status & & \\
\hline & Illiterate & 73 & $19.9 \%$ \\
\hline & Read and write & 73 & $19.9 \%$ \\
\hline & Primary education & 56 & $15.3 \%$ \\
\hline & Secondary school & 112 & $30.6 \%$ \\
\hline & College diploma/Degree & 52 & $14.2 \%$ \\
\hline \multirow[t]{5}{*}{5} & Religion & & \\
\hline & Orthodox & 199 & $54.4 \%$ \\
\hline & Muslim & 127 & $34.7 \%$ \\
\hline & Protestant & 33 & $9.0 \%$ \\
\hline & 0thers & 7 & $1.9 \%$ \\
\hline
\end{tabular}

\section{Satisfaction level of patient on clinical Laboratory Services}

Of 366 respondents, $194(53 \% \%)$ were satisfied, $111(30.3 \% \%)$ were neutral and $61(16.7 \% \%)$ were dissatisfied with general Laboratory service provided at selected health center( Figure 1) 


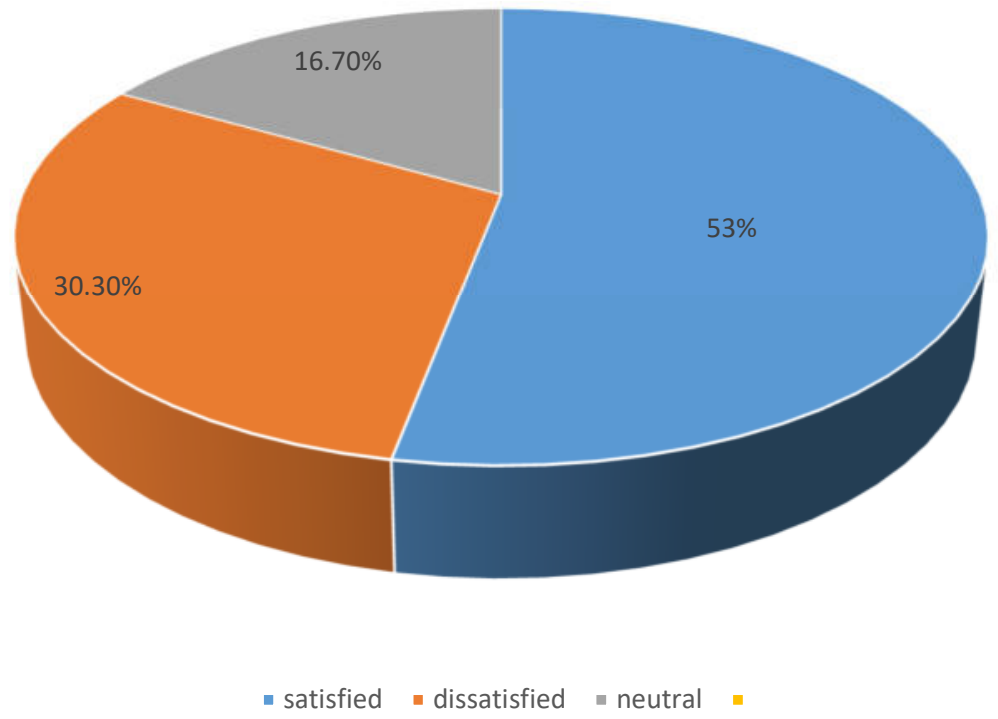

Figure 2: Level of patient's satisfaction on laboratory services at selected health center 2020(n=366)

The relationship between the CBHI beneficiary's level of satisfaction and independent variables

In Likert Scale, the overall mean rate of satisfaction of patients by laboratory services at Addis Ababa in selected health centers was 3.50. The mean rate of satisfaction for different aspects of laboratory services ranged from 2.79 to 3.80 . The lowest mean rating of satisfaction were given for the availability of service provider explained about diagnostic test during sample collection, Cleanliness and comfort of the latrine in the health centers with mean rating of 2.79 and 2.96 respectively. Higher mean rating of satisfaction was obtained for laboratory professional physical appearance (3.80), confidentiality (3.77), Cleanliness of the laboratory (3.77) and location of the laboratory (3.75) as indicated in (Table 2)

Table -2:-CBHI beneficiaries ratings of satisfaction with different aspects of clinical laboratory services given at Addis Ababa in selected health centers, 2020, $(n=366)$.

\begin{tabular}{|l|l|l|l|l|l|l|l|l|}
\hline & Variable & $\begin{array}{l}\text { Strongly } \\
\text { dissatisfied }\end{array}$ & Dissatisfied & Neutral & satisfied & $\begin{array}{l}\text { Strongly } \\
\text { satisfied }\end{array}$ & $\begin{array}{l}\text { Mean } \\
\text { rating }\end{array}$ & Satisfaction \\
\hline 1 & $\begin{array}{l}\text { Are you happy } \\
\text { with opening time }\end{array}$ & $20(5.5 \%)$ & $25(6.8 \%)$ & $183(50 \%)$ & $121(33.1 \%)$ & $17(4.6 \%)$ & 3.25 & $138(37.7 \%)$ \\
\hline 2 & $\begin{array}{l}\text { The availability of } \\
\text { the requested lab } \\
\text { test }\end{array}$ & $12(3.3 \%)$ & $35(9.6 \%)$ & $198(54.1 \%)$ & $106(29 \%)$ & $15(4.1 \%)$ & 3.21 & $121(33.1 \%)$ \\
\hline 3 & $\begin{array}{l}\text { Service provider } \\
\text { friendly }\end{array}$ & $13(3.6 \%)$ & $42(11.5 \%)$ & $114(31.1 \%)$ & $168(45.9 \%)$ & $29(7.9 \&)$ & 3.43 & $197(53.8 \%)$ \\
\hline 4 & $\begin{array}{l}\text { Location of the } \\
\text { laboratory }\end{array}$ & $9(2.5 \%)$ & $17(4.6 \%)$ & $68(18.6 \%)$ & $233(63.7 \%)$ & $39(10.7 \%)$ & 3.75 & $272(74.4 \%)$ \\
\hline 5 & $\begin{array}{l}\text { Cleanliness of the } \\
\text { laboratory }\end{array}$ & $6(1.6 \%)$ & $10(2.7 \%)$ & $93(25.4 \%)$ & $212(57.9)$ & $45(12.3 \%)$ & 3.77 & $257(70.2 \%)$ \\
\hline 6 & $\begin{array}{l}\text { The total waiting } \\
\text { time to get } \\
\text { laboratory result }\end{array}$ & $35(9.6 \%)$ & $63(17.2 \%)$ & $140(38.3 \%)$ & $106(29 \%)$ & $22(6 \%)$ & 3.05 & $128(35 \%)$ \\
\hline 7 & $\begin{array}{l}\text { Latrine } \\
\text { accessibility }\end{array}$ & $33(9 \%)$ & $46(12.6 \%)$ & $144(39.3 \%)$ & $129(35.2 \%)$ & $14(3.8 \%)$ & 3.12 & $143(39 \%)$ \\
\hline 8 & $\begin{array}{l}\text { Cleanliness and } \\
\text { comfort of the } \\
\text { latrine }\end{array}$ & $42(11.5 \%)$ & $65(17.8 \%)$ & $133(36.3 \%)$ & $116(31.7 \%)$ & $10(2.7 \%)$ & 2.96 & $126(34.4 \%)$ \\
\hline
\end{tabular}




\begin{tabular}{|c|c|c|c|c|c|c|c|c|}
\hline & Variable & $\begin{array}{l}\text { Strongly } \\
\text { dissatisfied }\end{array}$ & Dissatisfied & Neutral & satisfied & $\begin{array}{l}\text { Strongly } \\
\text { satisfied }\end{array}$ & $\begin{array}{l}\text { Mean } \\
\text { rating }\end{array}$ & Satisfaction \\
\hline 9 & \begin{tabular}{lr}
\multicolumn{2}{l}{ The availability of } \\
service provider \\
explained & about \\
diagnostic & test \\
during r sample & collection
\end{tabular} & $25(6.8 \%)$ & $122(33.3 \%)$ & $134(36.6 \%)$ & $76(20.8 \%)$ & $9(2.5 \%)$ & 2.79 & $85(23.3 \%)$ \\
\hline 10 & $\begin{array}{l}\text { Cleanliness of } \\
\text { blood drawing area }\end{array}$ & $3(0.8 \%)$ & $16(4.4 \%)$ & $134(36.6 \%)$ & $199(54.4 \%)$ & $14(3.8 \%)$ & 3.56 & $213(58.2 \%)$ \\
\hline 11 & $\begin{array}{l}\text { Availability of } \\
\text { laboratory staffs } \\
\text { on working time }\end{array}$ & $24(6.6 \%)$ & $38(10.4 \%)$ & $132(36.1 \%)$ & $156(42.6 \%)$ & $16(4.4 \%)$ & 3.28 & $172(47 \%)$ \\
\hline 12 & $\begin{array}{l}\text { Laboratory } \\
\text { personnel } \\
\text { professionals } \\
\text { appearance }\end{array}$ & $2(0.5 \%)$ & $16(4.4 \%)$ & $66(18 \%)$ & $252(68.9 \%)$ & $30(8.2 \%)$ & 3.80 & $282(77.1 \%)$ \\
\hline 13 & Confidentiality & - & $26(7.1 \%)$ & $68(18.6 \%)$ & $238(65 \%)$ & $34(9.3 \%)$ & 3.77 & $272(74.3 \%)$ \\
\hline 14 & $\begin{array}{l}\text { General } \\
\text { satisfaction by the } \\
\text { health center } \\
\text { laboratory service }\end{array}$ & $17(4.6 \%)$ & $60(16.4 \%)$ & $60(16.4 \%)$ & $189(49.5 \%)$ & $48(13.1 \%)$ & 3.50 & $237(62.6 \%)$ \\
\hline
\end{tabular}

Factors associated with level of patients' satisfaction on CBHI

The results from the cross-tabulations analysis showed that there was no significant relationship

Between age, sex, Educational background, marital status, and religion with level of patients' satisfaction laboratory services (table 3)

Table 3:-Comparisons of overall level of patients satisfaction with clinical laboratory services provided at selected health center and Socio Demographic, 2020. $(n=366)$

\begin{tabular}{|c|c|c|c|c|c|}
\hline \multirow[t]{2}{*}{ Variables } & \multicolumn{2}{|c|}{ Satisfaction no } & \multicolumn{3}{|c|}{ Chi square value } \\
\hline & satisfied & Dissatisfied & Df & X2 & p-value \\
\hline Age (years) & & & 4 & 1.639 & 0.996 \\
\hline $18-24$ & 19 & 30 & & & \\
\hline $25-34$ & 65 & 45 & & & \\
\hline $35-44$ & 91 & 25 & & & \\
\hline $45-55$ & 15 & 9 & & & \\
\hline$>55$ & 4 & 2 & & & \\
\hline Sex & & & 3 & 0.903 & 0.825 \\
\hline Male & 96 & 21 & & & \\
\hline Female & 98 & 90 & & & \\
\hline Marital status & & & 2 & 0.624 & 0.732 \\
\hline Married & 145 & 25 & & & \\
\hline Single & 46 & 83 & & & \\
\hline Divorced & 3 & 3 & & & \\
\hline Religion & & & 3 & 0.765 & 0.858 \\
\hline Orthodox & 149 & 19 & & & \\
\hline Muslim & 42 & 62 & & & \\
\hline Protestant & 0 & 27 & & & \\
\hline Others & 3 & 3 & & & \\
\hline Educational status & & & 4 & 1.944 & 0.746 \\
\hline Illiterate & 51 & 7 & & & \\
\hline Can read and write & 52 & 12 & & & \\
\hline Elementary school & 29 & 18 & & & \\
\hline Secondary school & 51 & 45 & & & \\
\hline College diploma/degree & 11 & 29 & & & \\
\hline
\end{tabular}

\section{Discussion}

Establishing health insurance services is gaining traction in resource-limited countries to improve health care 
utilization and ensure financial protection for households to mitigate against poverty. Patients are the ultimate customers of laboratory medicine and the importance of customer satisfaction in driving quality improvement has been increasing in laboratory medicine, Satisfaction of clients is one of the outcome measures for health care services and it serves as a useful quality improvement tool, required by most clinical laboratories (11).

This study has revealed that the overall satisfaction level of the CBHI beneficiaries with clinical laboratory services rendered at selected health centers in Addis Ababa was 53\%, and this is lower than reports from other studies conducted in wolaita Zone (91.38\%), Addis Ababa (59.7\%) and Nekemet (60.4\%), respectively $(28,32$, and 29). This is due to the excess flow of patient in the selected health centers laboratory leads the professionals was not capable to delivery of standard and quality services for the beneficiaries and understanding of the beneficiaries on the new program which is $\mathrm{CBHI}$ in the detailed explanation of the overall benefits of the program was not fully covered by the health centers laboratory services was the main reasons for lower satisfaction. However, this finding was comparable the findings in Eastern Ethiopia Hospitals, with patient satisfaction levels of $51.7 \%(31)$.

The mean rating of satisfactions for different aspects of clinical laboratory services in Addis Ababa at selected health centers laboratory services ranged from 2.79 to 3.80 . This range was lower as compared with some studies done in eastern Ethiopia (31). This could be due to differences in the living place life style for satisfaction and also might be the more chronic patients in Addis Ababa have a chance to pay extra payment for private diagnostic centers which is not available tests in the health center laboratory.

From different laboratory service given in Addis Ababa at selected health centers, the lowest mean rating of satisfaction were given for the availability of service provider explained about diagnostic test during sample collection, Cleanliness and comfort of the latrine in the health centers with mean rating of 2.79 and 2.96 respectively.

Higher mean rating of satisfaction was obtained for laboratory professional physical appearance (3.80), confidentiality (3.77), Cleanliness of the laboratory (3.77) and location of the laboratory (3.75) current study is higher than the finding in Tikur Anbesa (32). this is may the health centers is newly established building that is more appropriate designed for the location of laboratory and Cleanliness of the laboratory.

The level of satisfaction of the patients was no statistically significant association by age, sex, educational level, marital status and religion and which is similar to the finding by Nekemet referral hospital (29).

Higher rate of patient satisfaction was on the cleanliness of facility, laboratory professional physical appearance, and confidentiality. Lower rate was availability of service provider explained about diagnostic test during sample collection and latrine accessibility and comfort.

The study conducted in Addis Ababa (13) and Debre Markose Northern Ethiopia (14) reported that patients who were able to read and write and who had diplomas and above educational level were less likely to be satisfied with the laboratory service compared to those who cannot able to read and write, On the contrary, results of this study showed that there was no relationship between the educational status of the CBHI beneficiaries and their overall satisfaction with laboratory services this could be This could be due to the fact that most of patients were completing only secondary school; hence there was no difference in their expectations.

Some Study shows that the laboratory service was the main reason for the low customer satisfaction in the overall health services delivery (13), this study focus on the possible reason on specific laboratory services which have a great roll to the customer satisfaction for standard and quality services in clinical laboratory as well as the overall health services, this will increase the satisfaction of CBHI beneficiaries.

\section{Study limitation}

This study only focused on the demand side point of view (CBHI beneficiaries who enrolled), and the supply side view (provider side) was not explored and the study did not assess the association between satisfactions toward pre-laboratory services.

\section{Conclusion}

- The overall Household's satisfaction in CBHI on medical laboratory service done in selected health centers in Addis Ababa was moderate

- The level of satisfaction of the patients was no statistically significant association by age, sex, educational level, marital status and religion.

- The availability of service provider explained about diagnostic tests during sample collection, cleanness and comfort of the latrine and the total waiting time to get laboratory result was the main cause of low rating in the overall level of satisfaction in CBHL beneficiaries.

\section{Recommendations}

The overall recommendation is that selected health centers should strive to maintain the high standard it has in order to keep the CBHI beneficiaries satisfied with the services they receive. 
The health centers administrators and laboratory chiefs should work on the enhancement of laboratory services. Health centers administration needs to work with laboratory units in designing laboratory infrastructure such as waiting area and also in the latrine areas should solve the problem mentioned by CBHI beneficiaries.

A specific recommendation relates to the need to encourage the staff to treat patients with courtesy and respect in line with the Health Sector Reforms and patient-centered quality assurance. Allocate adequate man power to avoid delays and overcrowding. Lastly it a concerted effort to improve the explanation about diagnostic tests during sample collection and cleanliness, comfort also accessibility of the latrines is needed.

This CBHI program is newly launched in the capital city Addis Ababa since 2011E.C in few health centers so this study have a great resource for newly starting health centers and for those on the way to starting health centers to improve the overall laboratory services based on this finding.

\section{Acknowledgement}

First and foremost I would like to thank GOD, the most gracious, in helping me everything needed in my life in general and accomplish this task in particular.

Second I would like to give my heart full thanks to my advisor Fatuma Hassen and Alemayehu Nigatu in this study that encourages me to do good thesis to make my expectation to be true.

My thanks also extend to Ras Emiru health center and Felege Meles health center and also Departmental Research and Ethics Review Committee (DRERC) of School of Medical Laboratory Sciences, Addis Ababa University, for giving the ethical clearance.

\section{Disclosure}

The authors report no conflicts of interest in this work.

\section{Author contributions}

DG designed the study, writes up of the proposal, collected, analyzed, interpreted the data and drafted the manuscript. BL and EA participated in data collection, designing of the study and $\mathrm{FH}$ and AF contributed significantly in advising, editing, reviewing of both the proposal and manuscript.

\section{Reference}

1. Nerondwe.L, Odeku Ko. Financing the national insurance scheme of South Africa: opportunities and challenges. I soc sci. 2014, 39(1): $9-18$..

2. Wang W, Temsah G, Mallick L. The impact of health insurance on maternal health care utilization: evidence from Ghana, Indonesia and Rwanda. Health Policy Plan 2017; 32:366-75

3. Ekbladh L, Yenehun T Leulseged A.. Health Sector Financing Reform in Ethiopia: Lessons Learned and Ways Forward. Bethesda, October 2013.

4. Zelalem T, Abiyu M, Haji K and Getachew K. Clients and clinician satisfaction with laboratory services at selected government hospitals in eastern Ethiopia. BMC Research Notes 2013, 6:15

5. Mohammed S, Sambo MN, Dong H. Understanding client satisfaction with a health insurance scheme in Nigeria: factors and enrollees experi- ences. Health Res Policy Syst. 2011;9(1):20

6. Zelalem T, Abiyu M, Haji K and Getachew K. Clients and clinician satisfaction with laboratory services at selected government hospitals in eastern Ethiopia. BMC Research Notes 2013, 6:15

7 Abebe S,Hora T,Yohannes E,Tezera MB,Household satisfaction with a community-based health insurance scheme, BMC Res Notes (2016) 9:424

8. Rodas GA, Boaz A, Abota M, Hailu L, Abebe EN,Patient satisfaction with clinical laboratory services, Patient Preference and Adherence 2017:1

9. Geletta T, Eyasu E,Mikias D, Shibabew A, Keneni E Patients Satisfaction on Clinical Laboratory Services at Nekemte Referral Hospital, Oromia, Ethiopia, Food Science and Quality Managemen, Vol.30, 2014.

10. Million B, Seid A, Debela B, Derese D, Moges D, Misganaw B. HIV/AIDS patients' satisfaction on ARTlaboratory service in selected governmental hospitals, Sidamma Zone, Southern Ethiopia. Science Journal of Public Health2013; 1(2): 85-90.

11. Mohammed S, Sambo MN, Dong H. Understanding client satisfaction with a health insurance scheme in Nigeria: factors and enrollees experi- ences. Health Res Policy Syst. 2011;9(1):20

12.Abera RG, Abota BA, Legese MH, Negesso AE. Patient satisfaction with clinical laboratory services at Tikur Anbessa specialized hospital, Addis Ababa, Ethiopia. Patient Prefer Adherence. 2017;11:1181.

13.Asmamaw A, Yihalem AB,Patient satisfaction with clinical laboratory services and associated factors among adult patients attending outpatient departments at Debre Markos referral hospital, Northwest Ethiopia, BMC Res Notes (2019) 12:517 